\title{
Malformations of cortical development Current concepts and advanced neuroimaging review
}

\author{
Celi Santos Andrade1, Claudia da Costa Leite ${ }^{2}$
}

\begin{abstract}
Malformations of cortical development (MCD) result from disruptions in the complex process of the human brain cortex formation and are highly associated to severe epilepsy, neurodevelopmental delay and motor dysfunction. Nowadays, magnetic resonance imaging (MRI) is the cornerstone of the work-up of patients with epilepsy and modern advanced imaging techniques have improved not only our ability to detect and characterize cortical malformations, but also in identifying associated functional abnormalities that are far beyond the structural visualized lesions. Herein, we address the most currently used classifications of MCD and make a concise review of the embryological process of cortical development. Our main goal is to summarize recent advances and new trends in diagnostic imaging techniques concerning MCD. Thereafter, follows a brief discussion of specific disorders and their radiological features.
\end{abstract}

Key words: malformations of cortical development, epilepsy, magnetic resonance imaging, diagnostic imaging.

\section{Malformações do desenvolvimento cortical: conceitos atuais e revisão de neuro- imagem avançada}

\section{RESUMO}

As malformações do desenvolvimento cortical (MDC) resultam de distúrbios no complexo processo do desenvolvimento do córtex cerebral humano e estão comumente associadas a epilepsia severa e disfunções neuropsicomotoras. Atualmente, as imagens por ressonância magnética (RM) são a pedra angular no manejo de pacientes com epilepsia e modernas técnicas avançadas de imagem melhoraram não só a nossa capacidade de detectar e caracterizar as malformações corticais, mas também levaram ao reconhecimento de anomalias funcionais associadas que estão muito além das lesões estruturais visibilizadas. Abordaremos as classificações mais utilizadas de MDC e revisaremos a embriologia do desenvolvimento cortical. Nosso principal objetivo é destacar os avanços recentes e as novas tendências em técnicas de diagnóstico por imagens relacionadas às MDC. Em seguida, faremos uma breve discussão sobre alguns transtornos específicos e suas características radiológicas.

\section{Correspondence \\ Claudia da Costa Leite \\ Instituto de Radiologia \\ Setor de Ressonância Magnética \\ Av. Dr. Enéas de Carvalho Aguiar 255 \\ Portaria $5 / 3^{\circ}$ andar \\ 05403-001 São Paulo SP - Brasil \\ E-mail: claudia.leite@hcnet.usp.br}

\section{Support}

We are very grateful to FAPESP (CInAPCe project 05/56464-9) and to CNPq for the funding and support. Da. Claudia da Costa Leite was supported by CNPq (Grant 308267/008-7)

Received 20 July 2010

Received in final form 5 August 2010

Accepted 12 August 2010
Palavras-chave: malformações do desenvolvimento cortical, epilepsia, imagem por ressonância magnética, diagnóstico por imagem.
Malformations of cortical development (MCD) are highly epileptogenic lesions and some cases also present in childhood with early encephalopathy, neurodevelopmental delay, motor deficits and learning difficulties ${ }^{1-5}$. Neuroimaging is an extreme- ly important tool in the evaluation of patients with refractory epilepsy and constant advances in diagnostic imaging techniques have improved our ability in identifying focal lesions. Besides that, modern imaging studies have recently shown met-
Radiology Department, School of Medicine, University of São Paulo, São Paulo SP, Brazil: 'MD, Post-Graduate Radiologist of the Radiology Department, Clinics Hospital of University of São Paulo, School of Medicine, São Paulo SP, Brazil; ${ }^{2} \mathrm{MD}, \mathrm{PhD}$, Associate Professor of the Radiology Department of the University of São Paulo, School of Medicine, São Paulo SP, Brazil. Chief of the Neuroradiology Group and of the Magnetic Resonance Section, Clinics Hospital of University of São Paulo, School of Medicine, São Paulo SP, Brazil. 
abolic and functional abnormalities beyond the visible structural lesions, shedding light to the pathophysiological basis of human epileptogenesis.

The aim of this review is to address the current concepts of MCD and recent advances in modern imaging techniques concerning the diagnosis and understanding of these epileptogenic disorders. Before that, we will make a concise revision of the normal human brain cortex formation. For each subtype of MCD, we will state its histopathological, clinical and imaging characteristics with a pertinent differential diagnosis. Because of its medical and radiological significance, the following MCD will be addressed in this article: focal cortical dysplasia, hemimegalencephaly, heterotopia, lissencephaly, polymicrogyria, and schizencephaly.

\section{Classification of MCD and normal cortical development}

The study and classification of MCD are complicated by the fact that two malformations are virtually never completely identical and often combinations of different subtypes of malformations occur together in the same patient. Indeed, MCD have a wide spectrum of histomorphological alterations, heterogeneous clinical presentations and highly variable neuroradiological manifestations, that makes this group of diseases even more intriguing and somewhat challenging.

The most currently adopted categorization is the classification scheme of Barkovich et al. ${ }^{2,6,7}$, which is based on three embryological processes of brain development: neuronal and glial proliferation, and differentiation, and eventual apoptosis; neuronal migration; and cortical organization. These embryological steps should not be viewed as separate sequential processes, but as a complex mechanism that ultimately results in brain formation. The classification is based on the earliest stage at which the abnormality occurs, together with pathological, genetic and imaging aspects ${ }^{2,3}$.

The description of radial glia dates from the $19^{\text {th }}$ century and has strongly influenced the history of neuroscience ${ }^{8}$. The normal human brain cortical development is a so extraordinary and complex biological process, with so many molecular requirements, signaling cascades and precise expression patterns of key genes ${ }^{9-12}$, that one may wonder how is it possible not to have more commonly malformations and misdevelopments.

Neurons originate from stem cells of the subependymal layer of the wall of the ventricles (the so-called germinal matrix). The germinal matrix cells with neuronal differentiation (neuroblasts), when mature, begin a process of migration. The migration of neurons in the periventricular region to the deep nuclei and to the surface of the cerebral cortex is driven by radial fibers in the eighth week of gestation. The cerebellar nuclei and cortex are also formed in this period. The migration occurs in an orderly manner, so that the cells that will form the first layer of the cortex are the first to migrate and thereafter cells that will form the layers 6, 5, 4, 3 and 2. Cortical neurons migrate for varying distances until they reach the cortex in their final position, forming the hexalaminar cytoarchitecture of the adult neocortex ${ }^{9,10}$. After being organized in several layers, the neurons separate from the radial fibers and initiate the formation and growth of dendrites and synapses. The radial fibers are separated from the neurons after the migration and originate glial cells ${ }^{8}$. Most of the process of neuronal migration occurs around the $16^{\text {th }}$ week of gestation; however, this process will only end in about the fifth month of life. The cortical connections are formed very early, and continue to develop in an intricate mechanism that leads to the development of gray matter and white matter.

Brain sulcation and gyration are directly related to neuronal migration and are responsible for the increased cortical surface, without increasing its volume.

Disturbances in several molecular pathways ${ }^{11-15}$ that regulate these complex mechanisms may have a genetic basis ${ }^{3,10}$, although exogenous insults, such as cytomegalovirus infection, can also cause some types of MCD; the nature and timing of the insult in relation to the development process are the factors that determine the type of MCD.

\section{Modern neuroimaging techniques}

The diagnosis of any MCD ideally requires high resolution multiplanar magnetic resonance imaging (MRI ${ }^{6,16}$. This is by all means the method of choice for evaluation of the MCD because it demonstrates excellent contrast between white matter and gray matter, gives exact topographic characterization of the development of cortical gyri and sulci, and allows more accurate analysis of the formation of white matter and stages of myelination. Computed tomography (CT) scans can fail to make the diagnosis in more than $30 \%$ of affected patients ${ }^{2}$, but it is crucial to remember that this may be the only method available in some cases. Thus, it is important to recognize that CT changes, although subtle, are similar to those found in MRI studies.

New advanced MRI techniques have gradually improved image quality and reinforced our ability to identify, delineate and characterize brain lesions. According to some authors, the gain in spatial resolution with increasing magnetic field strength - moving from $1.5 \mathrm{~T}$ to 3.0 T, 7.0 T and greater - and subsequent increase in signal to noise ratio, can potentially bring more anatomical details in complex brain malformations ${ }^{16}$. Advances in multichannel coil technology, with phased array sur- 
face coils, have increased resolution and contrast of the acquired images ${ }^{16}$, with maximum gains in the cortical surface, which is especially useful in the detection of mild cortical dysplasias.

Some recent MR advanced sequences may also improve image quality and might be helpful in characterization of MCD. The introduction of volumetric T1-weighted sequences with high spatial resolution (SPGR - spoiled gradient recalled echo, MPRAGE - magnetization prepared rapid gradient echo) that allow high quality multiplanar reconstructions favors a more accurate diagnosis. Volumetric FLAIR at 3 Tesla can be very sensitive for characterizing subjacent white matter involvement ${ }^{16}$. Susceptibility weighted imaging (SWI), due to its increased contrast and resolution, has a potential role in delineating cortical lesions ${ }^{17}$.

Computer-assisted methods, such as voxel-based morphometry $(\mathrm{VBM})^{18}$, surface reconstructions and segmentation techniques ${ }^{19,20}$ may aid in detection of subtle lesions, but these automatic approaches still need to surpass intrinsic inaccuracies and remain to be proven helpful to the unassisted human eye in prospective studies ${ }^{16,18}$. Nevertheless, clinical information is still absolutely important in guiding the intensive and time-consuming visual search that is required in the evaluation of milimetric volume acquisitions with multiplanar reformats.

Improvements in fetal MRI with rapid pulse sequences, parallel imaging, more sophisticated coils and motion correction tools are also optimizing the early in utero detection of $\mathrm{MCD}^{16,21,22}$. The prenatal appearance of MCD is similar to that seen in the child and fetal MRI may detect malformations not visualized in sonography ${ }^{22}$. Besides that, the lack of myelination at this age may potentially make subtle cortical dysplasias easier to identify.

Although conventional MRI with high spatial resolution readily identify the malformed cortex in most cases, recent investigations have begun to look into the associated abnormalities in the white matter and cerebral connectivity by diffusion tensor imaging (DTI) and tractography ${ }^{23}$. Some studies have shown a reduction in the volume of white matter in the affected cerebral hemispheres containing the MCD and more widespread alterations in diffusivity and anisotropy, that could be of potential clinical importance if surgery is considered, and also in the investigation of cryptogenic epilepsy ${ }^{16,24}$.

Magnetoencephalography (MEG) may detect interictal epileptiform activity in up to one-third of electroencephalogram (EEG)-negative patients, by measuring very weak magnetic fields induced by neuronal discharges ${ }^{16,25}$. MEG seems to be useful in identifying cortical lesions and also mapping normally functioning eloquent cortex, thus improving overall surgical outcome ${ }^{26}$.

In the last decade, functional neuroimaging studies have also led to a better understanding of the pathophysiology of symptomatic epilepsy. Available techniques include single photon emission computed tomography (SPECT), positron emission tomography (PET), and functional magnetic resonance imaging (fMRI). SPECT scans showing changes in regional cerebral blood flow (rCBF) can predict the localization of an epileptogenic focus associated with an underlying abnormality, which may be particularly useful in the absence of obvious structural abnormality on $\mathrm{MRI}^{27}$. PET shows hypometabolism in the interictal phase, which can aid to lateralize the epileptogenic focus ${ }^{16}$. Studies using PET and fMRI demonstrated functional cortex located in MCD, confirming findings of invasive EEG and warning of the extreme care required when surgical resection is contemplated ${ }^{27}$. Despite widespread use of these diagnostic techniques in the presurgical evaluation, there are few studies specifically concerning MCD.

Leite and colleagues, in a study of multivoxel proton magnetic resonance spectroscopy (MRS) showed reduced levels of $\mathrm{N}$-acetylaspartate/creatine (NAA/Cr) in both the $\mathrm{MCD}$ and on the normal appearing contralateral side in patients with unilateral lesions, warning the fact that the metabolic abnormalities in MCD extend far beyond focal lesions evident on structural tests ${ }^{28,29}$. Others authors have also demonstrated metabolic abnormalities in MCD, such as reduced NAA and increased choline (Cho), as well as in the macroscopically normal perilesional zone, usually decreased NAA and $\mathrm{Cr}^{30-32}$.

Currently, our group is developing experiments with phosphorus MRS that can potentially bring more information on the phospholipid metabolism and brain energetic status in patients with MCD. Preliminary results have shown elevation of phosphocreatine ( $\mathrm{PCr}$ ) levels, which may correlate to hypometabolism in the interictal phase, and alterations in phosphomonoesthers (PME) and phosphodiesthers (PDE), which indicate a breakdown in the membrane synthesis. We also could note abnormalities in the contralateral normal appearing cerebral tissue $^{33}$.

The idea that in MCD the visible lesion represents only the "tip of the iceberg" has been widely debated. The presence of perilesional or contralateral metabolic abnormalities might be of clinical interest, particularly in patients in whom a surgical procedure is being considered. This could explain why surgical resection does not bring good results for the control of epilepsy in some patients with focal MCD ${ }^{34}$.

\section{Focal cortical dysplasia}

The great interest in focal cortical dysplasias (FCD) relies in the severity of clinical symptoms and the high frequency that this disorder is managed surgically. In 2004, 
Palmini et al. published a panel consensus on the terminology and classification of cortical dysplasias ${ }^{35}$.

FCD is an important cause of unfamiliar, non-syndromic, intractable epilepsy, with early onset in childhood. There are no features on physical examination suggestive of the diagnosis, although some reports of associated findings, such as linear epidermal nevus ${ }^{36}$. FCD is a major cause of focal motor epilepsy or continuous partial epilepsy that can be life threatening, so that surgical treatment is a therapeutic modality considered in many of these patients ${ }^{2,37,38}$.

Researchers have identified a variety of cytologic and histomorphologic abnormalities: giant pyramidal neurons, disorganized dysplastic neurons, "balloon" cells (large round cells with eosinophilic cytoplasm resembling a balloon), disordered lamination and clustering of neurons ${ }^{1,2,36,37,39-42}$. Evidences from in vitro studies show that cytomegalic neurons are primary epileptogenic cells, whereas "balloon" cells are electrophysiologically inactive ${ }^{38,43}$.

FCD are probably not a single entity. Indeed, the histological appearance is not uniform, ranging from molecular phenotypes, cytological components, organizational disturbances, genetic disorders, mechanisms of activation and appearance on MRI ${ }^{15,17,40}$.

FCD are characterized on MRI (Fig 1) as focal cortical thickening with abnormal signal intensity, blurring of the gray-white matter interface, sometimes with signal intensity abnormalities in the underlying white matter mostly hyperintense signal in T2 and FLAIR (fluid-attenuated inversion recovery) and hypointense signal in T1, with the aspect of a wedge-shaped tail extending radially

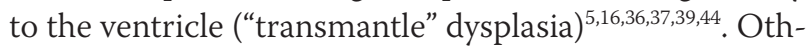
er characteristic imaging findings are focal white matter atrophy, a deep sulcus and broadening of the gyri adjacent to the FCD.
These changes are not always present together, nor are pathognomonic in isolation. FCD is usually found in frontal or temporal lobes, although it can occur in any location. Electroencephalogram (EEG) may show particular ictal changes in individuals. Detailed pre-surgical evaluation is mandatory, since FCD can occur in areas of eloquent cortex and the epileptogenic zone may be more extensive than the lesion visualized on $\mathrm{MRI}^{6,25,26,36}$.

This lesion can occasionally be quite subtle, and analysis of MR images together with clinical data, EEG and possibly nuclear medicine tests such as SPECT is essential for a correct assessment of the case and valorization of more subtle findings ${ }^{6}$. Sometimes superficial neuronal or neuroglial tumors like dysembryoplastic neuroepithelial tumor (DNET) and ganglioglioma can be a relevant consideration in the differential diagnosis, especially in less typical cases.

\section{Hemimegalencephaly}

Hemimegalencephaly or unilateral megalencephaly is related to the unilateral hamartomatous excessive growth of all or part of one cerebral hemisphere, with defects in neuronal proliferation, migration and cortical organization.

Affected patients typically have macrocephaly at birth, and can present early in childhood with refractory epilepsy, neurological development delay and hemiparesis ${ }^{45}$. Across this spectrum, milder cases may present with discrete seizures, completely controlled. The brain may be affected in isolation, or there may be hypertrophy of part or all of the ipsilateral body.

Some syndromes may be associated: neurofibromatosis type I, tuberous sclerosis, epidermal nevus syndrome, Proteus syndrome, ipsilateral hypomelanosis of Ito, Klippel-Trenaunay-Weber syndrome, focal alopecia, and dysembryoplastic neuroepithelial tumor ${ }^{1,2,14,44}$.
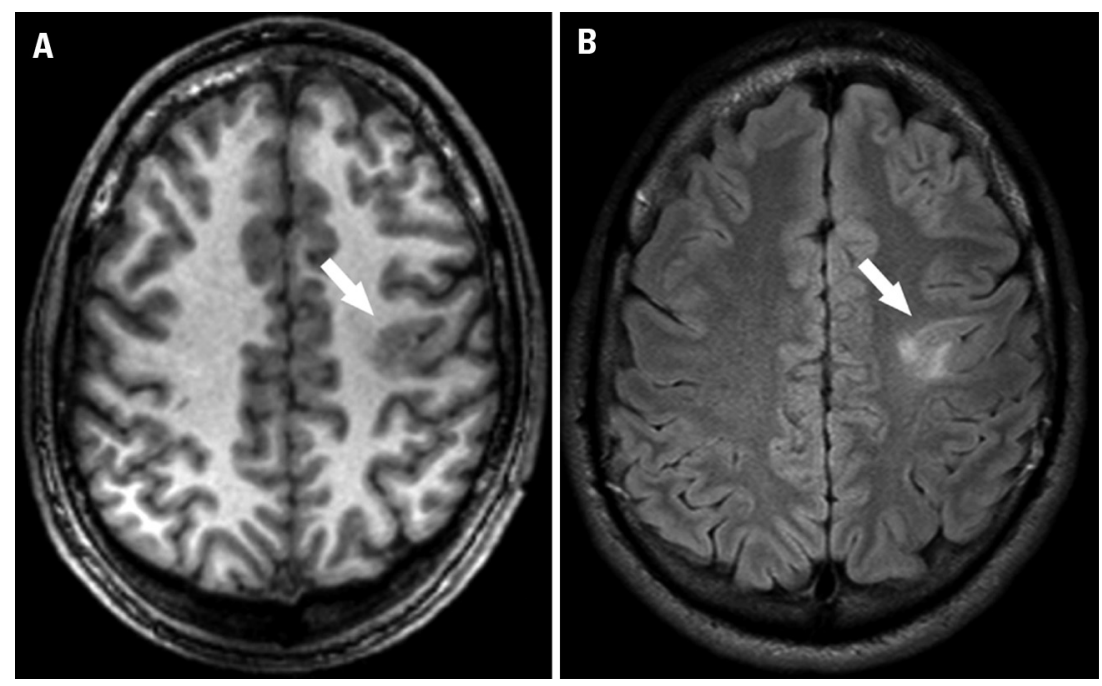

Fig 1. Focal cortical dysplasia. MRI performed at 3 Tesla exhibit an area of mild cortical thickening, with blurring of the white-gray matter interface in the left frontal lobe in the T1 FFE (fast field echo) axial image (arrow in A), that is also visualized in the FLAIR axial image, along with hyperintense signal in the underlying white matter (arrow in B). 

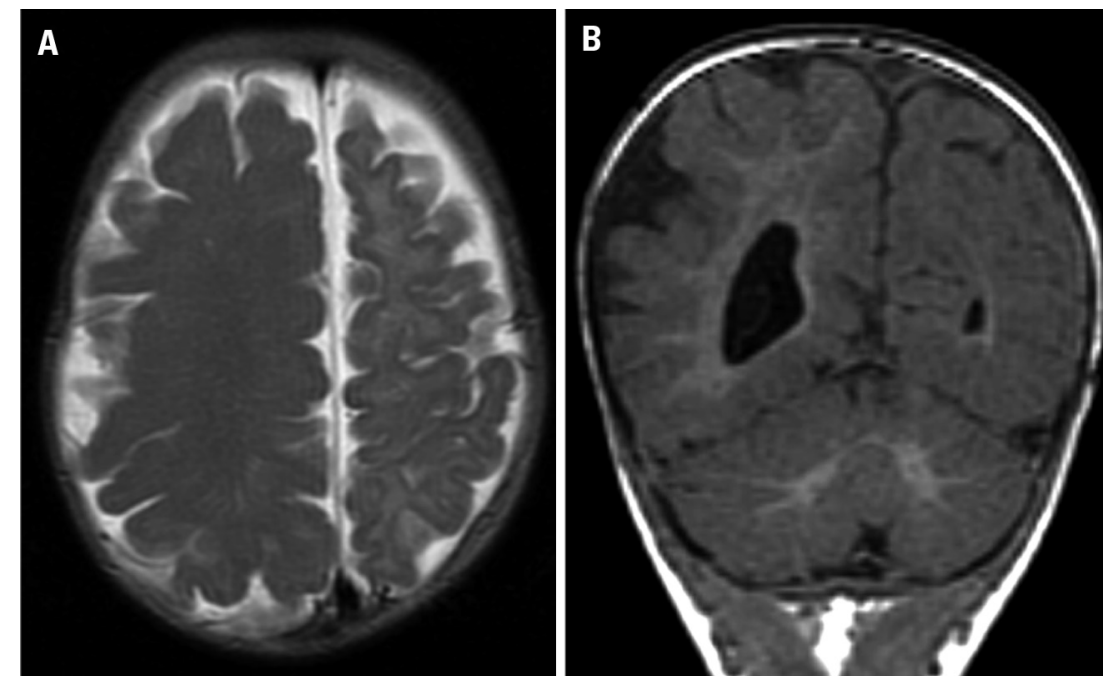

Fig 2. Hemimegalencephaly. Axial T2 FSE (fast spin echo) [A] shows an enlarged right cerebral hemisphere. 3D SPGR (spoiled gradient recalled echo) coronal reformat [B] also exhibits ipsilateral cortical thickening, with shallow sulci resembling pachygyria. Ventricular asymmetry is very conspicuous.
Anatomic or functional hemispherectomy may be indicated for clinically intractable epilepsy, if contralateral hemisphere is normal. The transfer of functions to the contralateral hemisphere is greater in younger children, due to brain plasticity.

Microscopically, laminar cortical organization is completely changed, with the presence of giant neurons in the cortex and in the underlying white matter. Histopathological studies usually demonstrate findings similar to those observed in cortical dysplasias ${ }^{14,40}$, with the presence of "balloon" cells in some cases"

MRI may show moderate to severe increase of the cerebral hemisphere, with increased volume of white matter, which may show in some cases abnormal signal. There is generally cortical thickening, with shallow sulci resembling agyria/pachygyria (Fig 2). The distinction of the interface between white matter and gray matter is usually blurred ${ }^{2,5}$. The lateral ventricle on the affected side is usually irregularly shaped and enlarged, in proportion to the increased cerebral hemisphere. However, in a few cases, the ipsilateral ventricle may be small ${ }^{2}$.

The main clue to the diagnosis of unilateral megalencephaly is the increase of the lateral ventricle on the affected side, contrary to what occurs in expansile or infiltrative lesions with mass effect, which compress and shift the ventricular system. In hemimegalencephaly, there is usually an association with other MCD, such as lissencephaly and polymicrogyria ${ }^{5}$.

\section{Heterotopia}

Heterotopia, one of the most commonly MCD revealed on MRI, occurs when neurons originating in the periventricular region fail to migrate, leaving tracks or nodules of neurons in heterotopic location, adjacent to the ependymal line or in subcortical topography. Based on MR images, there are three types of heterotopia: peri- ventricular nodular heterotopia, focal subcortical heterotopia, and band heterotopia.

The typical patient with periventricular nodular heterotopia (Fig 3) is most commonly female, during or after the second decade of life that presents with epilepsy, refractory or not to drug treatment. Usually there is no cognitive impairment and there are rare associations with disturbances outside the central nervous system, such as vasculopathy, patent ductus arteriosus or coagulopathy ${ }^{36}$.

Most cases of familial periventricular nodular heterotopia affect predominantly women and are caused by mutations in FLNA. However, mutations in this gene can also cause sporadic periventricular heterotopia in women as well as familial and sporadic cases in men. Other genes also appear to be involved, such as DCX, ARFGEF2 and a locus on chromosome $5 \mathrm{p}^{36,46}$.

Periventricular nodular heterotopia can be associated with mesial temporal sclerosis (dual pathology). In these cases, surgical resection of the affected hippocampus invariably brings no benefits and should be avoided ${ }^{36}$.

Patients with periventricular nodular heterotopia associated with other MCD compared to those with isolated periventricular heterotopia, have more severe clinical course, with more frequent seizures, failure to drug treatment and increased risk of mental retardation. The extent and distribution of subependymal nodules contraindicate surgery in most cases. Only a few patients were treated surgically, with varying results ${ }^{36}$.

The nodules of heterotopic gray matter can also occur in subcortical white matter (focal subcortical heterotopia) with distortion of the ventricle, unilaterally or bilaterally (Fig 4). There are reduction in the volume of white matter and thinning of overlying cortex. In these cases, more extensive clinical and cognitive deficits may ensue.

In band heterotopia (Fig 5), layers of gray matter are found in subcortical white matter, and are separated from 


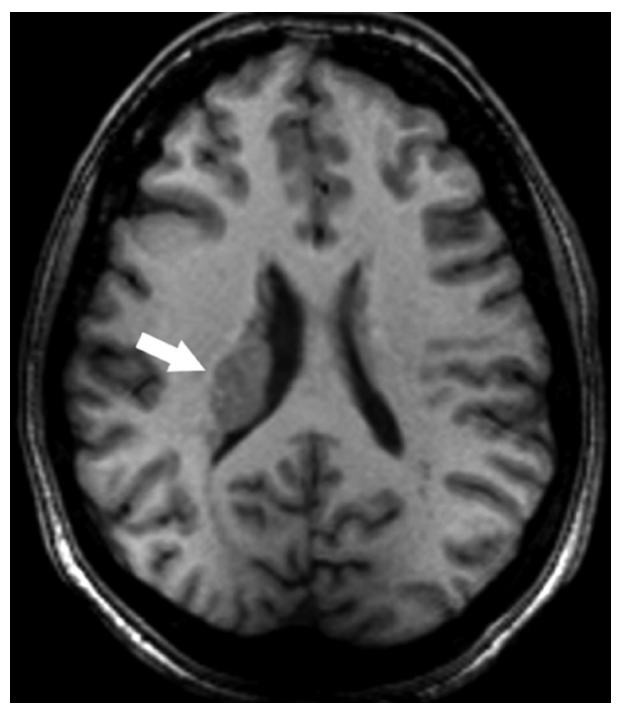

Fig 3. Periventricular nodular heterotopia. Volumetric T1 FFE (fast field echo) sequence performed at a 3 Tesla scanner with axial reconstruction in thin sections ( $1 \mathrm{~mm}$ thick) shows subependymal heterotopic gray matter adjacent to the right lateral ventricle (arrow).

the cortex by a thin layer of white matter. The thickness of the bands varies among patients and also along the fronto-occipital axis in the same individual. The thickness of the band is also related to the severity of the clinical picture, being more severe when there are thicker bands of gray matter ${ }^{36,45}$.

Histological specimens show heterotopic neurons with normal morphology in isolation or in clusters, but lacking appropriate synaptic connections. The pathophysiological basis is not completely understood and it seems that the gray matter nodules are intrinsically epileptogenic ${ }^{36}$.

Imaging diagnosis is usually obvious, showing periventricular or subcortical tissue isointense to gray matter on all sequences evaluated, that does not enhance after intravenous injection of paramagnetic contrast agent. In cases of band heterotopia, there is a characteristic configuration of "double cortex". The thickness of the bands varies, with blurring of the interface between the white matter and gray matter. Differential diagnosis includes subependymal nodules that occur in tuberous sclerosis, but these may enhance after contrast injection and may be calcified. The identification of the signal intensity similar to the gray matter on all MR sequences is the key to the correct diagnosis of gray matter heterotopia.

\section{Lissencephaly}

Lissencephaly is a rare cause of severe epilepsy, mental retardation and early death. However, MRI has shown that many patients survive into adulthood.

In lissencephaly, migration of all neurons is severely affected and the brain surface is smooth, with cortical

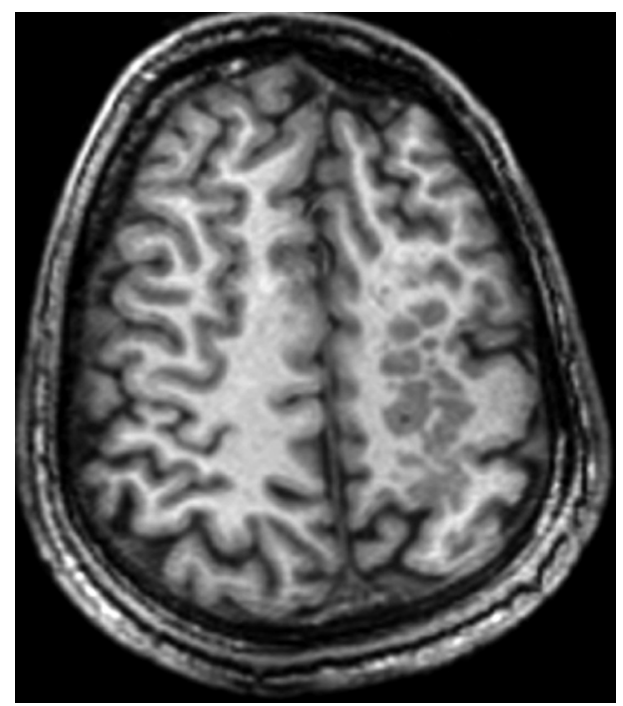

Fig 4. Subcortical heterotopia. T1 SPGR (spoiled gradient recalled echo) in the axial plane demonstrates multiple nodules isointense to gray matter in subcortical location in the left cerebral hemisphere. There can be also seen reduction in the volume of white matter, and thinning of the overlying cortex.

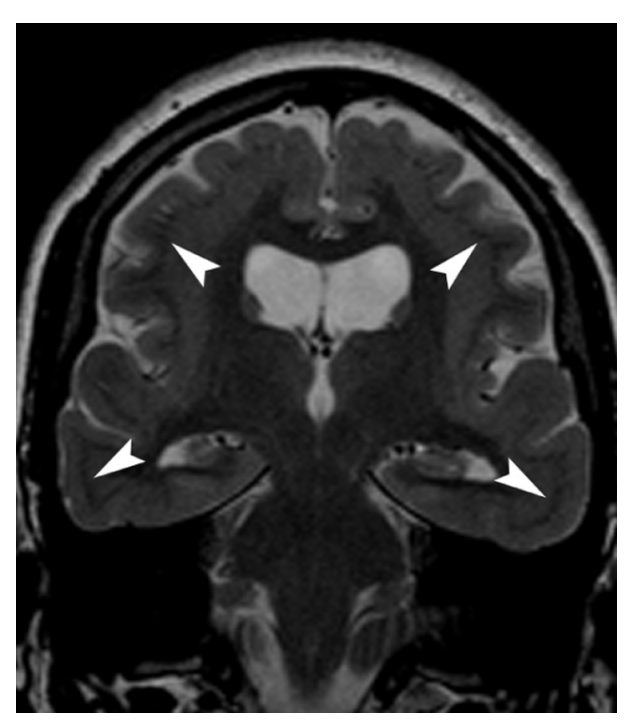

Fig 5. Subcortical band heterotopia. T2 weighted thin section in the coronal plane demonstrates a band of gray matter (arrowheads) in the frontal and temporal lobes, separated from the cortex by a thin layer of white substance, resembling a "double cortex". Figure kindly given by Dr. Fábio Eduardo Fernandes da Silva.

disruption and reduced white matter volume. The term agyria defines the complete absence of cerebral gyri on the cerebral surface and is synonymous of complete lissencephaly. Pachygyria represents a few large and thick gyri, with shallow sulci, and corresponds to incomplete lissencephaly ${ }^{2,5}$.

Studies in relatives with subcortical band heterotopia and others with lissencephaly have led to the discovery 


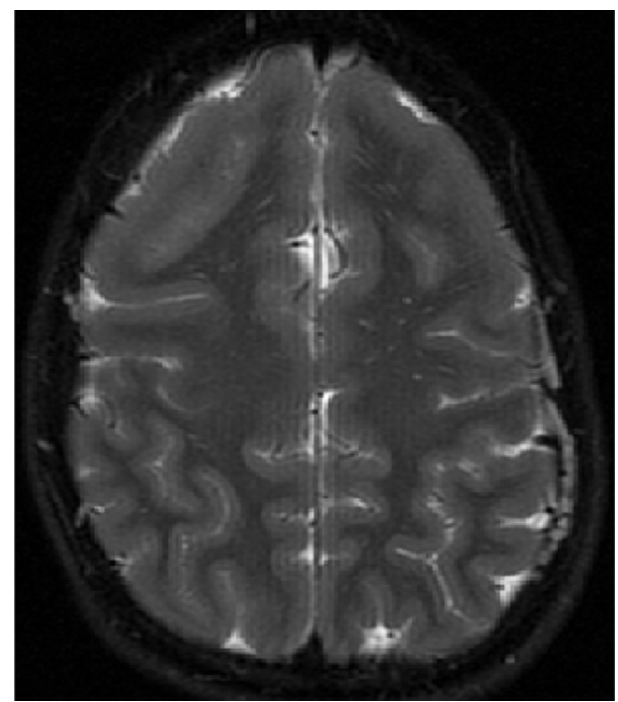

Fig 6. Lissencephaly. MR imaging (T2 FSE, axial plane) shows a smooth brain surface with no sulci on the anterior region (agyria), and a few shallow sulci posteriorly, with thick and broad gyri (pachygyria).

of new genes, $D C X$ on chromosome $\mathrm{X}$ and LIS1 on chromosome 17. Mutations in any of these genes can lead to any of these disorders or combinations of them, in men or women. Other genes also seem involved in the generation of this phenotype, such as YWHAE, ARX, TUBA1A and $R E L N^{2,3,5,36,41}$.

Lissencephaly may occur in isolation or as part of other syndromes. "Cobblestone" cortical malformations are mainly related to muscular dystrophy syndromes, clinically heterogeneous, but usually manifesting with hypotonia at birth, generalized muscle weakness and joint contractures in varying degrees. The diagnosis may be obtained by muscle biopsy, allied to characteristic imaging findings in the central nervous system. The three main disturbances in this group are Walker-Warburg syndrome, muscle-eye-brain disease, and Fukuyama congenital muscular dystrophy, ${ }^{5,41,44}$.

The Walker-Warburg syndrome shows characteristic imaging findings: hydrocephalus with marked ventriculomegaly, hypogenesis of corpus callosum, hypoplasia, and dysmorphism of brain stem and cerebellum, microphthalmia, and severe hypomyelination. Occipital cephaloceles are present in half of the cases ${ }^{2,5}$. The cortex is thick, with few shallow sulci and irregularity of gray-white matter junction, reflecting the extent of bundles of cortical neurons to the underlying white matter, hence the characteristic imaging appearance of the "cobblestone" cortex.

The Fukuyama congenital muscular dystrophy is a genetic condition, seen primarily in Japanese descendants with mutations in the FCMD gene on chromosome 9q31$33^{2}$. These patients have two main types of cortical anom- alies: polymicrogyria in the frontal lobes, and "cobblestone" cortex with shallow sulci predominantly in the posterior temporal, and occipital lobes. There are also cerebellar dysplasias with subcortical cysts, and delayed myelination of encephalic white matter ${ }^{5}$.

Muscle-eye-brain disease also features "cobblestone" cortex with irregular gray-white matter interface, cortical thickening (most pronounced anteriorly in the frontal lobes than posteriorly), with a reduction in number and depth of the sulci. There is severe hypomyelination, and the brain stem and cerebellum are dysmorphic. The pons is small, with an anterior slit, and there may also be fusion of the colliculi and presence of cerebellar cysts. The ocular globes are small, with subretinal fluid collections ${ }^{2,5}$.

There is no single effective drug treatment in patients with lissencephaly, and the epilepsy caused is usually refractory. Surgery in these patients is usually ineffective, but sometimes callosotomy may be considered.

Microscopically, there is disorganization of the lissencephalic cortex, and blurring of the interface with the white matter. If there is association with band heterotopia, layers of subcortical gray matter are composed of neurons similar to those found in cortical gray matter ${ }^{2}$.

In MRI, the cortical surface is smooth, the gyri may be scarce and flat (pachygyria) or absent (agyria) (Fig 6). Incomplete opercularization with shallow and verticalized sylvian fissures give an aspect of brain in "eight" or also called "snowman" or "hourglass" brain in the axial plane $^{44}$. In Walker-Warburg synd rome, the appearance of lissencephaly is typical, with the characteristic image of the "cobblestone" cortex.

Classic lissencephaly usually presents no great diagnostic challenge; however, pachygyria may sometimes be more subtle, close to the standard brain configuration usually found.

\section{Polymicrogyria}

Polymicrogyria is the presence of too many small abnormal gyri that produce an irregular cortical surface. Polymicrogyria is not invariably associated with epilepsy, and may present as neurological development delay, oromotor apraxia or congenital hemiparesis ${ }^{36,47,48}$.

Several patterns of inheritance have been described. A mutation in MECP2 has been found in a man with perisylvian syndrome and severe neonatal encephalopathy. A recent study involving hybrid genetic and MRI identified $P A X 6$ as a gene in which mutations can cause unilateral polymicrogyria ${ }^{36}$.

It has been reported clinical association with congenital arthtogryposis ${ }^{2,5,47}$ and with some specific syndromes, such as Delleman syndrome, Fukuyama congenital muscular dystrophy, Neu-Laxova syndrome, hypomelanosis of Ito, Aicardi syndrome, and diGeorge syndrome². 


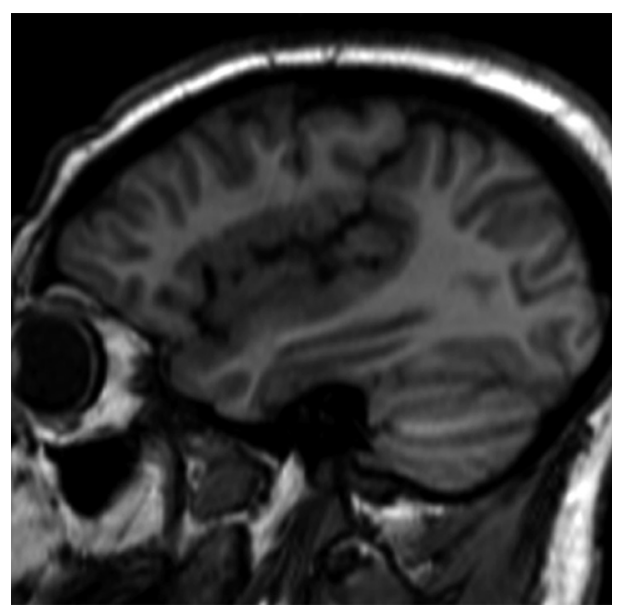

Fig 7. Perisylvian polymicrogyria. Imaging at 3 Tesla displays an operculum dysplastic and incomplete, with polymicrogyric cortex surrounding the sylvian fissure, which is vertically oriented and extends posteriorly to the parietal lobe, well demonstrated in the sagittal reformat of a volumetric T1-FFE (fast field echo) sequence.

Several particular patterns of polymicrogyria have been described; the main one is bilateral perisylvian polymicrogyria, clinically characterized by a combination of pseudobulbar palsy, spastic tetraparesis, learning difficulties and epilepsy. Some specific combinations of periventricular nodular heterotopia with overlying polymicrogyria have also been described ${ }^{3,46,48,49}$.

Moreover, the fact that there is necrotic tissue within the malformed cortex, that most changes occur in the middle cerebral artery territory, and the existence of polymicrogyria adjacent to the borders of schizencephaly and porencephaly, suggest that hypoxic-ischemic insults may, at least in some cases, be related to the genesis of polymicrogyria $^{5}$. There may also be a relation to congenital infections such as those caused by cytomegalovirus.

Some experimental models suggest that the epileptogenic area extends far beyond the obviously visualized abnormality. Resection of an isolated area rarely is beneficial in refractory epilepsy ${ }^{36}$.

At least two major histological types are recognized: the four-layered cortex with simplified organization (most common), and the unlayered type, yet there are several histological intermediate subtypes and these two main types can coexist in adjacent areas ${ }^{36,46}$.

MRI shows excessive cortical gyration with an aspect of cortical thickening and shallow sulci, and irregularity of the gray-white matter interface. This entity may be focal, multifocal or diffuse; unilateral or bilateral, symmetric or assymetric. In cases of perisylvian syndrome (Fig 7), there is polymicrogyria surrounding opercular portions with enlarged and vertically oriented sylvian fissures, extending to the parietal lobes, well demonstrated in the sagittal plane ${ }^{2,47}$.

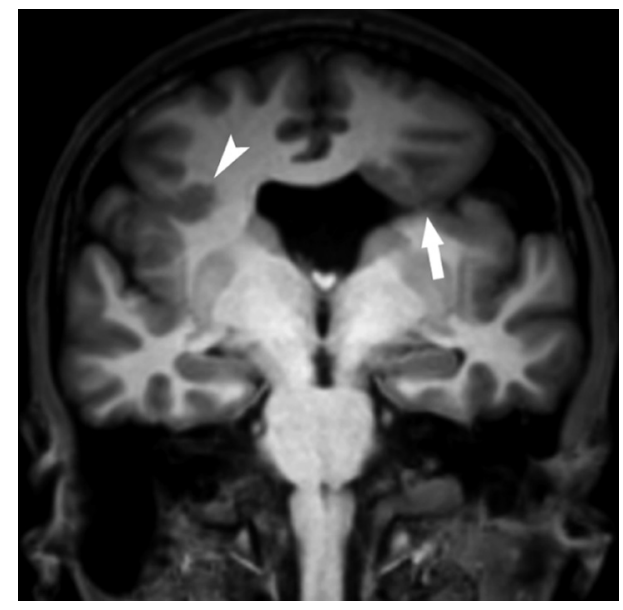

Fig 8. Schizencephaly. T1-weighted image in the coronal plane performed at 3 Tesla demonstrates an indentation ("nipple") in the left lateral ventricle, and a transcortical cleft extending from the ependymal to the pial surface (arrow). The cleft is lined by polymicrogyria, which can be also seen in the right frontal lobe (arrowhead). The septum pellucidum is absent.

Polymicrogyria may, in some contexts, simulate pachygyria, since excessive cortical gyration, when very small, simulates a thickened cortex with smooth surface, but these entities may be more easily distinguished in volumetric MRI sequences with high resolution images.

\section{Schizencephaly}

Schizencephaly is defined by the presence of a transcortical cleft, extending from the ventricular surface to the pial surface, lined with gray matter, and often with polymicrogyria along its edges.

There may be a variety of associated abnormalities involving the septum pellucidum, optic nerves, the corpus callosum or the hippocampi ${ }^{5}$. Septo-optic dysplasia (deMorsier syndrome) might be considered in a patient with schizencephaly, optic nerve hypoplasia and absence of septum pellucidum ${ }^{5,44}$. As in polymicrogyria, vascular, infectious and genetic causes have been considered in the genesis of this malformation ${ }^{2,46}$, and perhaps the severity of the insult differentiates these two entities, being more severe in the case of schizencephaly.

There may be a wide spectrum of clinical presentations. Patients with bilateral clefts usually have microcephaly and severe developmental delay, with spastic quadriparesis, while patients with unilateral clefts may have much less severe clinical phenotypes ${ }^{2}$. Surgical treatment has been reported in cases of medically intractable epilepsy, but it is rarely considered.

Usually the cleft is lined by dysplastic gray matter, and there may be adjacent areas of polymicrogyria, pachygyria and heterotopic gray matter nodules ${ }^{46}$.

MRI shows a transcortical cleft which may be apposed 
together (closed lips, type I) or clearly unapposed (open lips, type II), communicating the ventricle with the periencephalic subarachnoid space, lined by gray matter ${ }^{5}$. The lesions may be unilateral or bilateral (in this case, usually symmetrical in location but not in size). In a closed lips schizencephaly, the presence of an indentation in the ependymal surface may be the most significant clue to the correct diagnosis, the so-called nipple (Fig 8).

The greatest differential here is between open lips schizencephaly and porencephaly. Both are lesions with signal intensities similar to cerebrospinal fluid, but the tissue that lines the cavity is the key to the correct diagnosis - if it shows signal intensity characteristics similar to gray matter, the hypothesis of schizencephaly can be safely considered.

In summary, recognition of the main patterns of MCD in MR images is the mainstay in the work-up of these patients, and advanced neuroimaging techniques may aid in the correct diagnosis, leading to a more accurate classification of these complex and highly epileptogenic entities.

\section{REFERENCES}

1. Guerrini R, Sicca F, Parmeggiani L. Epilepsy and malformations of the cerebral cortex. Epileptic Disord 2003;5(Suppl):S9-S26.

2. Kuzniecky RI, Jackson GD. Magnetic Resonance in Epilepsy. 2 ed. Oxford: Elsevier; 2005.

3. de Wit MC, Lequin MH, de Coo IF, et al. Cortical brain malformations: effect of clinical, neuroradiological, and modern genetic classification. Arch Neurol 2008;65:358-366.

4. Tinuper P, D'Orsi G, Bisulli F, et al. Malformation of cortical development in adult patients. Epileptic Disord 2003;5 (Suppl 2):S85-S90

5. Barkovich AJ, Raybaud CA. Malformations of cortical development. Neuroimaging Clin N Am 2004;14:401-423.

6. Colombo N, Salamon N, Raybaud C. Imaging of malformations of cortical development. Epileptic Disord 2009:11:194-203.

7. Barkovich AJ, Kuzniecky RI, Jackson GD. A developmental and genetic classification for malformations of cortical development. Neurology 2005: 65:1873-1887.

8. Bentivoglio M, Mazzarello P. The history of radial glia. Brain Res Bull 1999; 49:305-315.

9. Sidman RL, Rakic P. Neuronal migration, with special reference to developing human brain: a review. Brain Res 1973:62:1-35.

10. Valiente $\mathrm{M}$, Marín O. Neuronal migration mechanisms in development and disease. Curr Op Neurobiol 2010;20:68-78.

11. Kriegstein A, Noctor S, Martínez-Cerdeño V. Patterns of neural stem and progenitor cell division may underlie evolutionary cortical expansion. Nature Rev 2006;7:883-890

12. Kubo K, Nakajima K. Cell and molecular mechanisms that control cortical layer formation in the brain. Keio J Med 2002:52:8-20.

13. Battaglia G, Becker AJ, LoTurco J, et al. Basic mechanisms of MCD in animal models. Epileptic Disord 2009;11:206-214

14. Crino PB. Focal brain malformations: seizures, signaling, sequencing. Epilepsia 2009;50 (Suppl 9):S3-S8.

15. D'Arcangelo G. From human tissue to animal models: insights into the pathogenesis of cortical dysplasia. Epilepsia 2009;50 (Suppl 9):S28-S33.

16. Madan N, Grant E. New directions in clinical imaging of cortical dysplasias. Epilepsia 2009;50:9-18.

17. Jensen FE. Introduction - epileptogenic cortical dysplasia: emerging trends in diagnosis, treatment, and pathogenesis. Epilepsia 2009:50 (Suppl 9):S1-S2.

18. Bruggemann JM, Wilke M, Som SS, Bye AM, Bleasel A, Lawson JA. Voxelbased morphometry in the detection of dysplasia and neoplasia in childhood epilepsy: Iimitations of grey matter analysis. J Clin Neurosci 2009; 16:780-785.

19. Dale AM, Fischl B, Sereno MI. Cortical surface-based analysis. I. Segmentation and surface reconstruction. Neuroimage 1999;9:179-194.

20. Fischl B, Sereno MI, Dale AM. Cortical surface-based analysis. II: Inflation, flattening, and a surface-based coordinate system. Neuroimage 1999;9: 195-207.
21. Glenn OA, Barkovich AJ. Magnetic resonance imaging of the fetal brain and spine: an increasingly important tool in prenatal diagnosis: part 1. AJNR Am J Neuroradiol 2006;27:1604-1611.

22. Glenn OA, Barkovich J. Magnetic resonance imaging of the fetal brain and spine: an increasingly important tool in prenatal diagnosis: part 2. AJNR Am J Neuroradiol 2006;27:1807-1814.

23. Lim CCT, Yin H, Loh NK, Violet GE, Francis H, Barkovich AJ. Malformations of cortical development high-resolution MR and diffusion tensor imaging of fiber tracts at 3T. Am J Neuroradiol 2005:26:61-64.

24. Eriksson SH, Rugg-Gunn FJ, Symms MR, Barker GJ, Duncan JS. Diffusion tensor imaging in patients with epilepsy and malformations of cortical development. Brain 2001;124:617-626.

25. Knake S, Halgren E, Shiraishi H, et al. The value of multichannel MEG and EEG in the presurgical evaluation of 70 epilepsy patients. Epilepsy Res 2006; 69:80-86.

26. Knowlton RC. Can magnetoencephalography aid epilepsy surgery? Epilepsy Curr 2008:8:1-5.

27. Cross JH. Functional neuroimaging of malformations of cortical development. Epileptic Disord 2003;5(Suppl):S73-S80

28. Leite CC, Lucato LT, Sato JR, Valente KD, Otaduy MCG. Multivoxel proton MR spectroscopy in malformations of cortical development. Am J Neuroradiol 2007:28:1071-1075

29. Leite CC. Malformações do desenvolvimento cortical: avaliação através da espectroscopia de prótons com aquisição simultânea de múltiplos volumes de interesse: Faculdade de Medicina da Universidade de São Paulo. Tese. São Paulo; 2003

30. Mueller SG, Laxer KD, Barakos JA, et al. Metabolic characteristics of cortical malformations causing epilepsy. J Neurol 2005;252:1082-1092.

31. Li LM, Cendes F, Bastos AC, Andermann F, Dubeau F, Arnold DL. Neuronal metabolic dysfunction in patients with cortical developmental malformations: a proton magnetic resonance spectroscopic imaging study. Neurology 1998;50:755-759.

32. Kuzniecky R, Hetherington $\mathrm{H}$, Pan J, et al. Proton spectroscopic imaging at 4.1 tesla in patients with malformations of cortical development and epilepsy. Neurology 1997:48:1018-1024.

33. Andrade CS, Otaduy MCG, Maia DF, Valente KDR, Leite CC. Phosphorus MR spectroscopy at high filed in patients with malformations of cortical development - preliminary results. In: XXXIII Brazilian Epilepsy Congress. Brasília; 2010.

34. Roulet-Perez E, Davidoff V, Mayor-Dubois C, et al. Impact of severe epilepsy on development: recovery potential after successful early epilepsy surgery. Epilepsia 2010;51:1266-1276.

35. Palmini A, Najm I, Avanzini G, et al. Terminology and classification of the cortical dysplasias. Neurology 2004;62(Suppl 3):S2-S8.

36. Sisodiya SM. Malformations of cortical development: burdens and insights from important causes of human epilepsy. Lancet Neurol 2004;2:29-38.

37. Colombo N, Citterio A, Galli C, et al. Neuroimaging of focal cortical dysplasia: neuropathological correlations. Epileptic Disord 2003;5 (Suppl 2):S67-S72.

38. Duchowny M. Clinical, functional, and neurophysiologic assessment of dysplastic cortical networks: Implications for cortical functioning and surgical management. Epilepsia 2009;50 (Suppl 9):S19-S27.

39. Sisodiya SM, Fauser S, Cross JH, Thom M. Focal cortical dysplasia type II: biological features and clinical perspectives. Lancet Neurol 2009:8:830-843.

40. Blumcke I, Vinters HV, Armstrong D, Aronica E, Thom M, Spreafico R. Malformations of cortical development and epilepsies: neuropathological findings with emphasis on focal cortical dysplasia. Epileptic Disord 2009;11:181-193.

41. Crino PB, Miyata H, Vinters HV. Neurodevelopmental disorders as a cause of seizures: neuropathologic, genetic, and mechanistic considerations. Brain Pathol 2002:12:212-233.

42. Chamberlain WA, Cohen ML, Gyure KA, et al. Interobserver and intraobserver reproducibility in focal cortical dysplasia (malformations of cortical development). Epilepsia 2009;50:2593-2598.

43. Mathern GW, Cepeda C, Hurst RS, Flores-Hernandez J, Mendoza D, Levine MS. Neurons recorded from pediatric epilepsy surgery patients with cortical dysplasia. Epilepsia 2000;41 (Suppl 6):S162-S167.

44. Leite CC, Amaro JE, Lucato LT. Neurorradiologia - Diagnóstico por imagem das alterações encefálicas. São Paulo: Guanabara Koogan; 2008.

45. Guerreiro MM. Malformations of cortical development. Arq Neuropsiquiatr 2009;67:570-574

46. Guerrini R, Marini C. Genetic malformations of cortical development. Exp Brain Res 2006;173:322-333.

47. Poduri A, Chitsazzadeh V, D'Arrigo S, et al. The syndrome of perisylvian polymicrogyria with congenital arthrogryposis. Brain Dev 2009;32:550-555.

48. Leventer RJ, Jansen A, Pilz DT, et al. Clinical and imaging heterogeneity of polymicrogyria: a study of 328 patients. Brain 2010;133:1415-1427.

49. Wieck G, Leventer RJ, Squier WM, et al. Periventricular nodular heterotopia with overlying polymicrogyria. Brain 2005;128:2811-2821. 